\title{
CARACTERIZAÇÃO DO DESENVOLVIMENTO RURAL SUSTENTÁVEL NO MUNICÍPIO DE VENDA NOVA DO IMIGRANTE-ES
}

\author{
Valdeberto de Castro Monteiro' \\ Edevaldo de Castro Monteiro² \\ Erica Aparecida Hott ${ }^{3}$
}

Resumo: A produção de alimentos em grande escala tornou-se assunto recorrente nos últimos anos. $A$ necessidade de renovar e ou manter os recursos naturais para as próximas gerações é o tema de extrema relevância, pois há um crescente interesse da população pelo ambiente natural, motivo que tem despertado o setor de agroturismo, sendo este o grande precursor do desenvolvimento para no município de Venda Nova do Imigrante-ES, como uma fonte de renda familiar, demonstrando-Ihes assim como o homem e a natureza interagem em harmonia. Neste contexto, o objetivo e mostrar que o homem pode usufruir da natureza sem degradá-la e manter ativa as tradições de seus antepassados. Contudo conclui-se que o desenvolvimento rural tem como abrangência a preservação da cobertura vegetal nativa, tornando um atrativo para o desenvolvimento rural sustentável que é o agroturismo, onde se tem o uso e a conservação do solo e da água uma atenção especial e ao mesmo tempo proporciona a renda aos agricultores.

Palavras-chave: Agricultura; Agroturismo; Sustentabilidade.

\footnotetext{
${ }^{1}$ Licenciado em Geografia /Centro Universitário Claretiano - CUC, Brasil. E-mail: valdeberto.cm@gmail.com.

2 Tecnólogo em Cafeicultura e Graduando em Engenharia Agronômica/Universidade Federal Rural do Rio de Janeiro- UFRRJ, Seropédica - RJ, Brasil. E-mail: ecmonteiro@hotmail.com.

${ }^{3}$ Ciências Contábeis/Faculdade do Sudeste Mineiro- FACSUM, Brasil. E-mail: ericaaphott@gmail.com.
} 